\title{
Marijuana Smoking: Factors That Influence the Bioavailability of Tetrahydrocannabinol
}

\author{
Mario Perez-Reyes
}

\section{INTRODUCTION}

Marijuana smoking is the most commonly used method for the selfadministration of delta-9-tetrahydrocannabinol (THC) the active principle of marijuana. The inhalation of marijuana smoke induces subjective effects ("high") that are rapidly perceived by the smokers. The perception of these effects allows smokers the capacity to achieve, within certain limits, their desired level of high by changing the puff volume, the interval between puffs, and the number of puffs taken. Therefore, the manner in which marijuana cigarettes are smoked (smoking dynamics) is probably the mast important factor in determining the bioavailability of THC. However, the following factors are also important: (1) the potency of the marijuana smoked; (2) the amount of unchanged THC present in the smoke inhaled (i.e., the amount of THC not destroyed by pyrolysis); (3) the amount of THC lost in side-stream smoke; (4) the method of smoking (cigarette vs. pipe smoking); and (5) the amount of THC trapped in the mucosa of the upper respiratory tract. A review of the experiments we have conducted that permit evaluation of the relative importance of these factors is presented in this chapter.

\section{METHODS COMMON TO ALL CLINICAL STUDIES}

\section{Subjects}

Male and female, healthy, paid volunteers who used marijuana no more than two times per week participated in the studies. They were thoroughly informed about the experimental procedures, the purpose of investigation, and the potential risks. All signed an informed consent approved by the Committee on the Protection of the Rights of Human Subjects of the University of North Carolina at Chapel Hill. 


\section{Experimental Variables}

Subjective Ratings of Intoxition. The major psychologic effect of marijuana is a temporary euphoric effect with diversely perceived sensory, somatic, affective, and cognitive changes that are commonly described as a high. To measure this effect, we asked the subjects to rate their degree of high at frequent intervals during the experiment on a graph form provided for them. For this rating, the subjects were asked to estimate their level of high on a scale of 0 to 100; zero represented no effect and 100 represented the highest they had ever been after smoking marijuana. Every time a rating was to be made, subjects were given their previous rating to use for comparison. This technique allowed the subjects to rate themselves as experiencing relatively more, less, or the same effects as those rated in the previous time interval.

Physiologic Effects. Since the most consistent physiologic effect of marijuana in humans is cardiac acceleration, the ECG was continuously recorded on a polygraph before the beginning of smoking (baseline) and throughout the duration of the experiment. The results are reported as. the percentage of heart rate acceleration over baseline values.

Determination of the THC Plasma Concentration. Blood samples were drawn through an indwelling needle before the initiation of smoking and at frequent intervals thereafter. The plasma obtained was analyzed by standard radioimmunoassay procedures (Owens et al. 1981; Cook et al. 1982).

\section{Statistical Analyses}

For comparison, the means of the data plus or minus the standard errors of the mean (SEM) were calculated and are reported as such throughout the text. Areas under the curve (AUCs) were calculated by the trapezoidal rule method. The results were analyzed statistically by means of regression analysis and $\mathrm{t}$ test for either dependent paired data or independent nonpaired data as appropriate.

\section{MARIJUANA POTENCY}

To investigate the influence that marijuana potency per se has on the peak THC plasma concentrations produced, a regression analysis was done on the results of experiments in which National Institute on Drug Abuse (NIDA) marijuana cigarettes of eight different potencies (range 1 percent to 6.24 percent THC) were smoked. The marijuana potencies investigated, the number of subjects tested, the mean peak THC plasma concentrations, and the range of individual peak THC plasma concentrations are illustrated in figure 1 . The results indicate the presence of a statistically significant correlation between the potency of the marijuana smoked and the peak THC plasma concentrations $(\mathrm{r}=.269, \mathrm{r}=2.27$, one-tailed $\mathrm{p}<.025)$. However, as 
shown in this figure, wide individual variations in peak THC plasma concentrations occurred consistently across all of the marijuana potencies investigated. This variability in THC plasma concentrations indicates that factors other than the potency of the marijuana smoked, particularly the smoking dynamics, influence the magnitude of the resulting THC plasma concentrations.

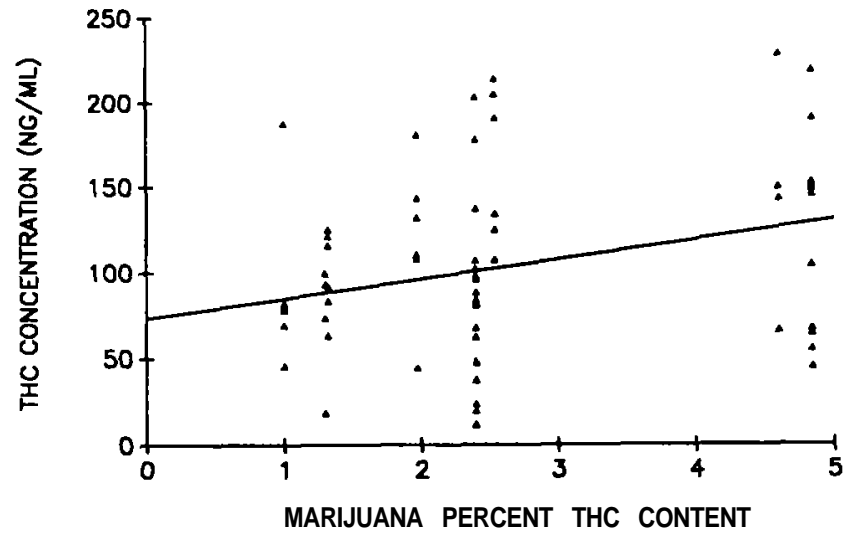

$\begin{array}{ccrc}\text { THC CONTENT } & \text { SUBJECTS } & \text { THC }(\mathrm{ng} / \mathrm{ml}) & \text { RANGE } \\ 1.00 \% & 6 & 90.4 \pm 20.2 & 45.6-187.8 \\ 1.30 \% & 4 & 71.3 \pm 18.4 & 18.7-99.6 \\ 1.32 \% & 6 & 100.0 \pm 10.1 & 62.8-125.3 \\ 1.97 \% & 6 & 119.8 \pm 10.6 & 44.5-180.9 \\ 2.40 \% & 18 & 63.0 \pm 8.6 & 11.7-137.0 \\ 2.40 \% & 6 & 119.0 \pm 23.0 & 81.0+203.0 \\ 2.54 \% & 6 & 162.6 \pm 18.7 & 107.4-204.7 \\ 4.60 \% & 4 & 146.3 \pm 33.1 & 65.7-227.6 \\ 4.84 \% & 12 & 124.2 \pm 16.2 & 44.8-218.0\end{array}$

FIGURE 1. Relationship between marijuana potency and THC plasma concentration (top) and marijuana potency and peak THC plasma concentration $(\mathrm{ng} / \mathrm{ml})$ (bottom)*

$*_{\mathrm{r}=269 ;} \mathrm{p}=.025$

NOTE: In the upper part of the figure, the Individual peak THC plasma concentrations of 68 volunteers are plotted against the THC content of the NIDA marijuana cigarettes that they smoked. In the lower part of the figure, the numerical values measured are summarized. 


\section{PYROLYTIC DESTRUCTION}

When marijuana is smoked, a portion of its THC content is destroyed by pyrolysis before reaching the mouth of the smoker. Information regarding the amount of THC destroyed by pyrolysis is derived from both cigarettes and water-pipe smoking.

\section{Cigarette Smoking Study}

Davis and colleagues (1984) conducted a study in which standard NIDA marijuana cigarettes containing 1.6 percent and 3.1 percent THC were smoked by a cigarette-smoking machine in a constant draft mode, i.e., the cigarettes were artificially inhaled in a single puff until nothing was left. The percent of the original THC not recovered in the smoke condensate collected and probably lost to pyrolysis was $30.6 \pm 1.4$ and $30.9 \pm 1.2$ for the 1.6 percent and the 3.1 percent THC content cigarettes, respectively. Since no measurement of the THC trapped in the smoking apparatus was done, the total amount actually lost to pyrolysis, under their experimental conditions, was probably less than 30 percent.

\section{Water-Pipe Smoking Study}

Marijuana water-pipe smoking replicates artificial single-draft smoking because the amount of plant material placed in the bowl of the pipe is entirely combusted, and the smoke produced is inhaled in a single puff. One milligram of Vitiated THC was added to $70 \mathrm{mg}$ of placebo marijuana (0.004 percent THC) and placed in the bowl of a commercially available water pipe. One bowl was smoked every 2.5 minutes, for a total of 10 bowls. The six volunteers who participated in this study were instructed to draw air until the total amount of marijuana placed in the pipe's bowl was combusted and to inhale the total amount of smoke produced in a single puff. A Cambridge filter, to trap the THC content of the smoke produced, was placed between the mouth of the pipe and the mouth of the subjects. The amount of THC recovered from the pipe, the plant material residues, and the Cambridge filters was measured by gas liquid chromatography. It was found, in this unpublished study, that $40.4 \pm 1.5$ percent of the original amount of THC was trapped in the Cambridge filters (i.e., approximately the amount of THC that would have reached the mouth of the subjects if the marijuana smoke had not been filtered), and that $40.2 \pm 4.5$ percent of the original amount of THC remained in the pipe and plant material residues (figure 2). Therefore, since approximately 80 percent of the original amount of THC was recovered, it can be concluded that 20 percent was destroyed by pyrolysis.

The results of these smoking studies, given the large margin of error introduced by differences in methodology, compare favorably and indicate that between 20 percent and 30 percent of the THC contained in the plant 
material is destroyed by pyrolysis during single-draft smoking conditions, irrespective of the marijuana potency smoked.

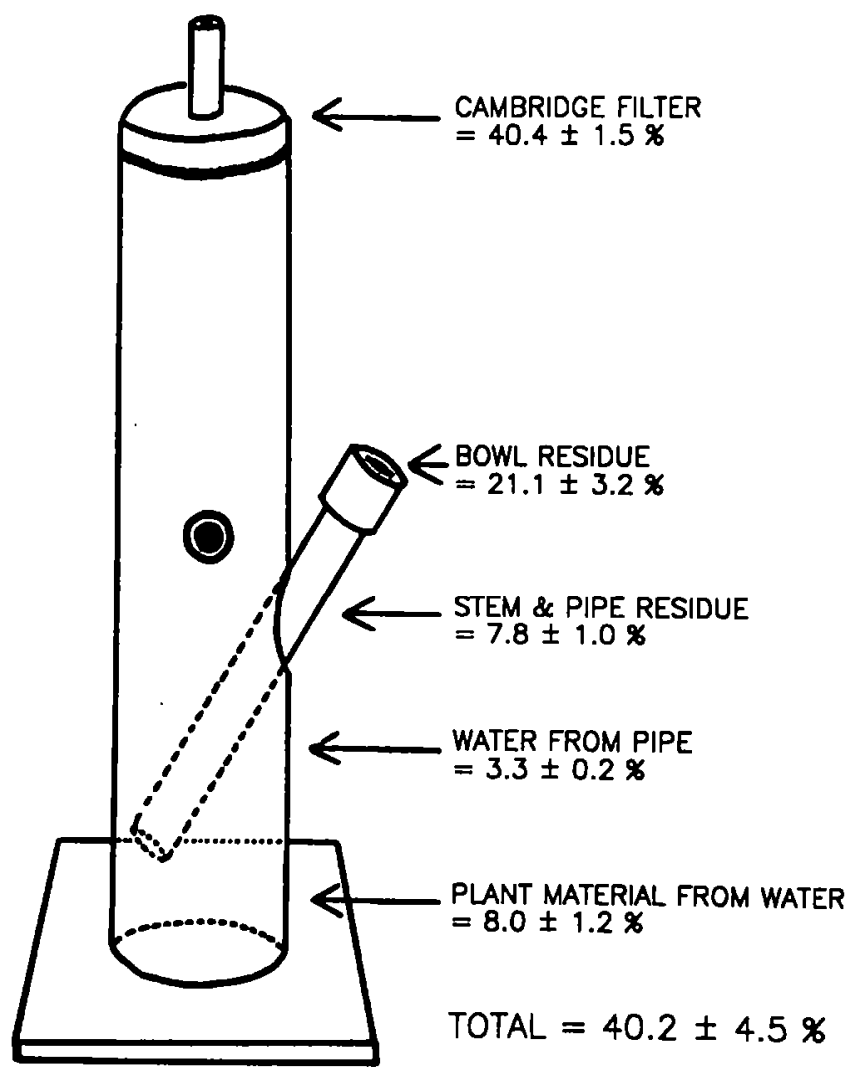

FIGURE 2. Diagram of the water pipe used in THC studies

NOTE: The amount of THC recovered from the pipe components and the amount of THC that was potentially inhaled by the subjects (i.e. the THC trapped in the Cambridge filter) are indicated.

\section{SIDESTREAM SMOKE}

When marijuana cigarettes are combusted, the smoke produced is either inhaled when puffs are taken (mainstream smoke) or escapes to the 
atmosphere during the interval between puffs (sidestream smoke). To have an approximate measure of the amount of THC present in mainstream smoke and lost in sidestream smoke when marijuana cigarettes are smoked by machine, experiments were conducted by Davis and associates (1983). In these experiments, standard MDA marijuana cigarettes containing 1.6 percent and 3.1 percent THC were smoked by a cigarette-smoking machine. Two modes of smoking were investigated, continuous inhalation (i.e., the cigarettes were inhaled in a single puff until nothing was left) and intermittent inhalation (the cigarettes were inhaled at a rate of two 40-ml puffs per minute). The results of these experiments indicate that marijuana potency did not significantly influence the percent of THC present in mainstream smoke within either mode of artificial smoking, i.e., 69.4 \pm 1.4 and $69.1 \pm 1.2$ percent for continuous smoking and 19.0 \pm 1.2 and $16.1 \pm 0.6$ percent for intermittent smoking, respectively, for the 1.6 percent and 3.1 percent THC-content cigarettes. Assuming that the amount of pyrolytic destruction of $\mathrm{THC}$ is the same between constant and intermittent smoking, the difference in the amount of THC present in mainstream smoke between the two modes of smoking indicates that between 40 percent and 50 percent of the original THC content of the cigarettes was lost in side stream smoke (figure 3).

MAIN STREAM SMOKE (20-378)

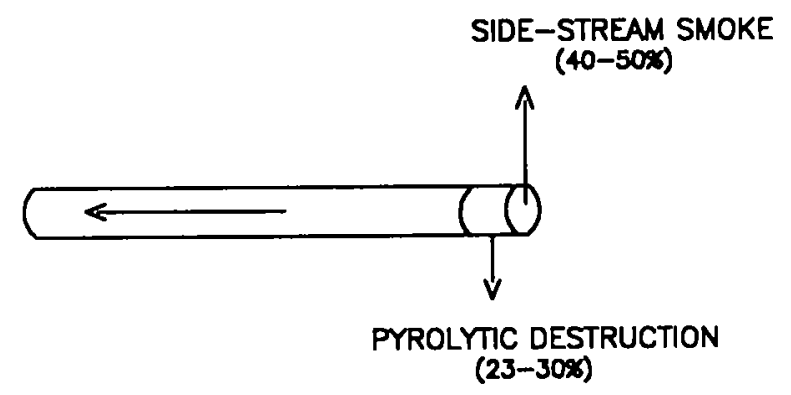

FIGURE 3. Fate of THC during marijuana cigarette smoking

NOTE: The percent of THC that potentially reach the mouth of the subject (mainstream smoke) and that lost to pyrolysis and sidestream smokc when marijuana cigarettes are smoked. Percent values are approximations.

The results of clinical studies of marijuana cigarette smoking (Perez-Reyes et al. 1982) indicate that, on the average, smokers puff more often (2.6 puffs per minute) than the puff frequency used in the Davis cigarettesmoking study (2 puffs per minute) (Davis et al. 1983). Therefore, it is reasonable to assume that when subjects smoke marijuana cigarettes, the amount of THC lost in sidestream smoke is not as large as that found in the cigarette-smoking-machine experiments. Nevertheless, this loss should 
still be of considerable magnitude because the cumulative interpuff interval (the time when the cigarette is idly smoking) accounts for 90 percent of the total smoking time (table 1).

TABLE 1. Smoking parameters for two modes of marijuana cigarette smoking

\begin{tabular}{|c|c|c|c|c|}
\hline & \multicolumn{2}{|c|}{ Accelerated Smoking $(n=4)$} & \multicolumn{2}{|c|}{ Slow Smoking $(n=6)$} \\
\hline & $1.51 \% \mathrm{THC}$ & $2.87 \%$ THC & $1.32 \%$ THC & $254 \% \mathrm{THC}$ \\
\hline Smoking time $(\min )$ & $5.2 \pm 0.9$ & $6.2 \pm 1.0$ & $17.9 \pm 2.0$ & $17.2 \pm 2.1$ \\
\hline Number of puffs & $18.3 \pm 2.3$ & $17.0 \pm 2.3$ & $30.7 \pm 5.1$ & $31.5 \pm 4.0$ \\
\hline Puff duration (sec) & $2.0 \pm 0.2$ & $1.8 \pm 0.1$ & $2.0 \pm 0.4$ & $2.3 \pm 0.3$ \\
\hline Interpuff interval (sec) & $18.3 \pm 2.5$ & $22.5 \pm 4.2$ & $20.7 \pm 2.8$ & $21.0 \pm 2.4$ \\
\hline Total puff duration (sec) & $31.9 \pm 3.8$ & $30.4 \pm 5.4$ & $56.2 \pm 6.3$ & $74.3 \pm 13.8$ \\
\hline Total interpuff interval (rain) & $4.7 \pm 0.9$ & $5.7 \pm 0.9$ & $16.9 \pm 2.0$ & $15.9 \pm 2.0$ \\
\hline $\begin{array}{l}\text { Plasma THC, time to peak } \\
\text { (min) }\end{array}$ & $6.5 \pm 1.0$ & $5.0 \pm 1.2$ & $6.7 \pm 0.6$ & $7.7 \pm 0.8$ \\
\hline $\begin{array}{l}\text { Plasma THC, peak value } \\
(\mathrm{ng} / \mathrm{ml})\end{array}$ & $210.8 \pm 44.0$ & $229.6 \pm 46.4$ & $100.0 \pm 10.1$ & $162.6 \pm 18.7$ \\
\hline Mean puff volume (ml) & $55.8 \pm 10.6$ & $49.2 \pm 6.8$ & & \\
\hline Total puff volume (ml) & $889.0 \pm 92.0$ & $818.0 \pm 106.0$ & & \\
\hline
\end{tabular}

NOTE: Data obtained in studies in which marijuana cigarettes of comparable potency were smoked by the volunteers in one instance through a puff-volume measuring instrumcnt (acceleratcd smoking), and in the other instance without it (slow smoking).

\section{SMOKING DYNAMICS}

\section{Marijuana Cigarette Smoking}

We have conducted studies in which the number of puffs, the puff duration, the interval between puffs, and the duration of marijuana cigarette smoking of similar (Perez-Reyes et al. 1981) or different (Perez-Reyes et al. 1982) potencies were measured. However, in these studies, the critically important puff volume parameter was not measured. To fill this gap in the knowledge of the dynamics of marijuana cigarette smoking, we conducted experiments in which the puff volume was measured throughout the period of smoking.

To measure the puff volume, a cigarette-holder flow-rate transducer based on the Venturi's flow meter was used (Hutcheson et al. 1984). The signal from this pressure transducer was amplified, filtered, and then routed to a PDP 11/34 Laboratory computer for processing by an online program that 
computed puff volume, puff duration, inter-puff interval, cumulative puff volume, and cumulative smoking time.

Using this technology, NIDA marijuana cigarettes containing 1.51 percent and 2.87 percent THC were smoked at weekly intervals in a double-blind crossover design by four male volunteers. To imitate natural conditions as much as possible, the volunteers were instructed to smoke the cigarettes in their customary fashion and to smoke until they had reached their desired level of high or for as long as they wished. Blood samples for the determination of the THC plasma concentrations were collected.

\section{Results}

Smoking Time. For comparison, the results obtained in this study in which the cigarettes were smoked through the puff-volume transducer and those obtained in a study in which cigarettes of comparable potency were smoked without this device are illustrated in table 1. Examination of the data shows a profound difference in mean smoking time between the two studies. We hypothesized that the presence of the cigarette-holder puff-volume transducer in front of the subjects' faces provoked them into an unintended accelerated rate of smoking. Accelerated smoking did not affect the mean puff duration or the mean interval between puffs. The mean number of puffs was decreased, however, and as a consequence the mean cumulative interval between puffs was shorter.

Puff Volume. As shown in table 1, the mean puff volume and the mean cumulative puff volume were not significantly influenced by the potency of the marijuana smoked. The mean puff volumes observed during the period of smoking are shown in figure 4. The similarity of the smoking pattern between the groups is apparent, as is the progressive decrease in puff volumes over time. To investigate the significance of this pattern, the cumulative puff volume inhaled by each subject during the first half was compared to that which occured during the second half of their smoking period (figure 5). The differences in mean cumulative puff volumes between cigarette halves are statistically significant: $\mathrm{t}=3.22, \mathrm{p}<.05$, and $\mathrm{t}=4.53, \mathrm{p}<.02$ for the 151 percent and the 2.87 percent THC content marijuana, respectively.

THC Plasma Concentration. For each comparable marijuana potency smoked, the magnitude of the THC plasma concentrations during the time of observation (figure 6) and the mean peak THC plasma concentrations measured (table 1) were larger in response to accelerated smoking. This finding may be due to the large individual variation in THC plasma concentrations (figure 1), as different volunteers participated in the studies. This could also be due to a faster rate of THC delivery during accelerated smoking studies. 


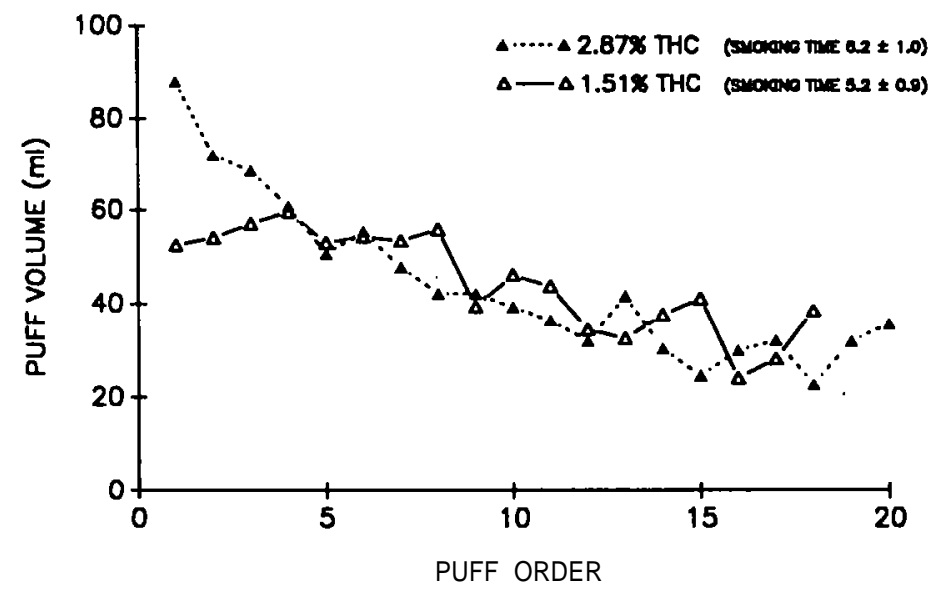

FIGURE 4. Comparison of mean puff volume

NOTE: Mean smoke volumes inhaled per puff during the period of smoking. It can be seen that the twofold difference in marijuana potency did not change the smoking profile.

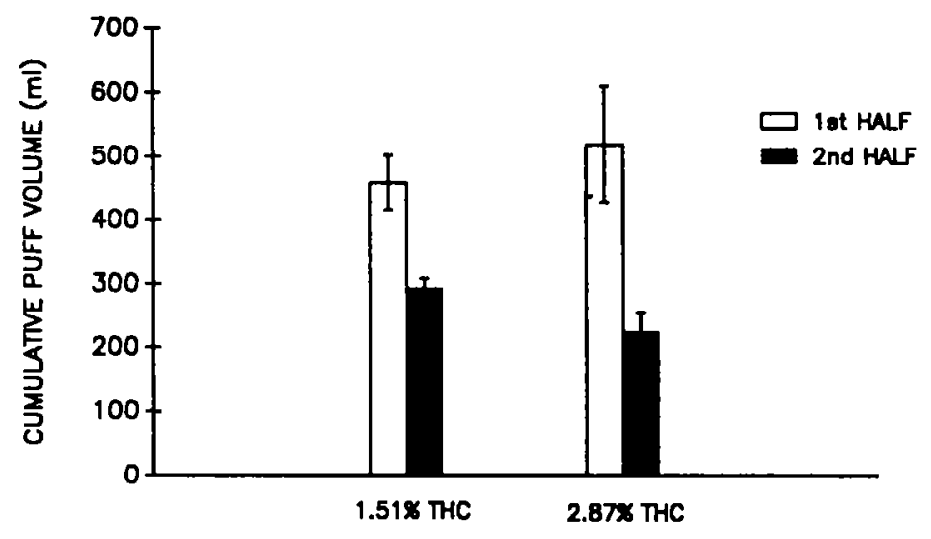

FIGURE 5. Comparison of the cumulative puff volume (total smoking time divided into halves)

NOTE: A larger mean cumulatlve smoke volume was inhaled during the first half of the cigarettes. The difference between marijuana potencies is not statistically significant. 
(SLOW SMOKING)

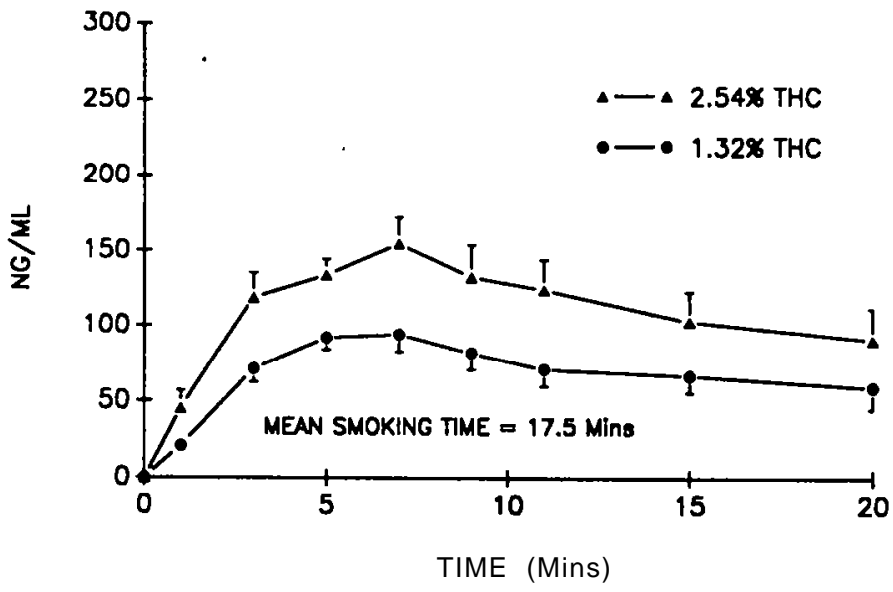

(ACCELERATED SMOKING)

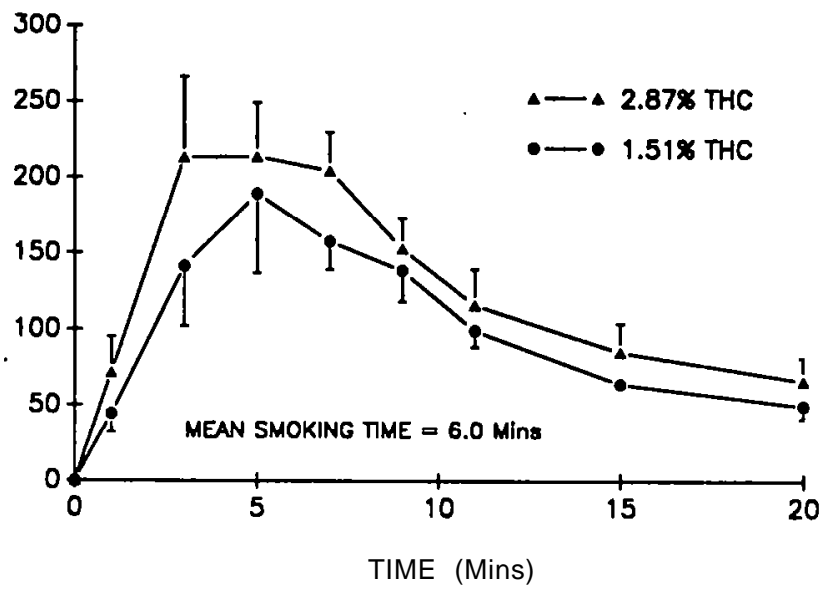

FIGURE 6. Comparison of the mean THC plasma concentration between slow and accelerated smoking

The relationship between THC time to peak and the smoking time observed in response to slow smoking reported in table 1 indicates that THC plasma concentrations sometimes peaked several minutes before the termination of smoking. As shown in figure 7 , this relationship has been consistently 
observed in the many marijuana-smoking experiments that we have previously conducted. ThiS observation was always intriguing because it was contrary to the reasonable expectation that for as long as the smoke produced by the combustion of marijuana cigarettes was inhaled, the resulting THC plasma concentrations should have continued to increase until smoking was terminated. Therefore, it was unexpected to find that, during accelerated smoking, the THC plasma concentrations peaked at approximately the same time that smoking was terminated. We hypothesized that rapid inhalation of marijuana smoke resulted in a rate of delivery of THC to the bloodstream that was faster than the drug's rate of disappearance into the extravascular compartment. In contrast, when the rate of inhalation of marijuana smoke was slow, the drug's rate of disappearance into the extravascular compartment was faster than the rate of delivery of THC to the bloodstream.

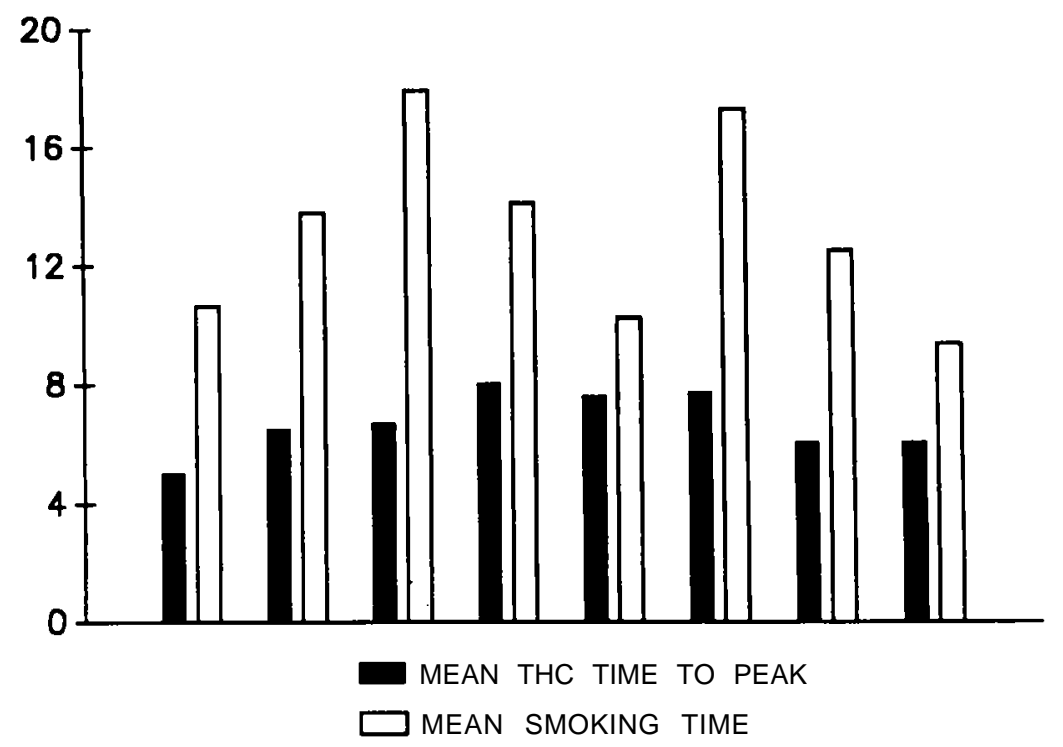

FIGURE 7. Relationship between smoking time and THC time to peak

NOTE: The results of eight separate studies in which marijuana cigarettes were smoked in the volunteers customary manner are shown. It can be seen that peak THC plasma concentrations cosistently occurred before the termination of smoking. 


\section{Marijuana Water-Pipe Smoking}

Marijuana is frequently smoked in pipes of different sixes and configurations, particularly in water pipes, because they cool the smoke and facilitate its inhalation. This method of smoking has become more popular in recent years because it permits the combustion of small portions of high-potency marijuana (sometimes as high as 13 percent THC in Sinsemilla plant material).

As discussed, marijuana cigarette smoking of identical THC content results in large interindividual variations in THC plasma concentrations. This is because the number of puffs taken, the interval between puffs, and the volume of smoke inhaled per puff vary greatly from person to person. In contrast, marijuana pipe smoking permits control of the number of puffs taken, the interval between puffs, and the volume of smoke inhaled per puff. Moreover, at least theoretically, the amount of plant material placed in the bowl of the pipe should be entirely combusted, all of the smoke produced should be inhaled, and practically no THC should be lost in sidestream smoke. We hypothesized that under these controlled smoking circumstances, less interindividual variation in the magnitude of THC plasma concentrations should occur.

To verify this hypothesis, we conducted three dose-response studies, using a single-blind crossover design in which marijuana of different potencies was smoked in a $250-\mathrm{ml}$ capacity water pipe (figure 2). A wire screen was placed at the bottom of the pipe's bowl to prevent uncombusted plant material from dropping into the pipe. A constant amount of water was used to fill the pipe, which provided a consistent 200-ml volume of air space between the mouth of the subject and the water level (the puff volume).

The volunteers were instructed to inhale the total amount of smoke produced by the combustion of the marijuana placed in the pipe's bowl ("toke") and to hold the smoke in their lungs for 10 seconds. Smoke inhalation was facilitated by the drawing of atmospheric air through a small hole located above the water level. Tokes were taken at $0,2.5,5,7.5$, and 10 minutes. This rate of administration was selected because in our previous studies in which radiolabeled 'H-THC was smoked in a water pipe, the resulting THC plasma concentrations were sustained during the period of smoking.

Experimental Variables. To determine the peak THC plasma concentrations produced, blood samples were drawn through an indwelling needle at appropriate intervals. The subjective rating of marijuana high was measured at frequent intervals throughout the experiments, and the heart rate was recorded before and after marijuana smoking in only the second and third studies. 
Drug Dosage. In our initial study, $0.625 \mathrm{mg} / \mathrm{kg}$ of marijuana containing 1.68 percent or 2.51 percent THC was combusted per toke. The amount of smoke produced by the combustion of this amount of marijuana was large, and some of the six volunteers who participated in the study had difficulties combusting the tokes completely or inhaling the total amount of smoke generated. For this reason, a second dose-response study was conducted in which the amount of plant material combusted per toke was reduced to $0.5 \mathrm{mg} / \mathrm{kg}$ for marijuana containing 2.51 percent $\mathrm{THC}$ and to $0.4 \mathrm{mg} / \mathrm{kg}$ for marijuana containing 3.12 percent THC. The latter marijuana potency was obtained by mixing equal parts of 6.24 percent and 0.004 percernt THC. The amount of smoke produced by the combustion of tokes containing $0.5 \mathrm{mg} / \mathrm{kg}$ was still large enough that some of the six volunteers who participated in this study had difficulty inhaling the smoke completely. However, the amount of smoke generated by the combustion of the $0.4 \mathrm{mg} / \mathrm{kg}$ tokes was completely inhaled without difficulty. The pharmacologic effects obtained in this study were of greater magnitude than those obtained in the first study, but they were leas pronounced than those produced by the smoking of marijuana cigarettes. In an effort to obtain larger pharmacologic effects, a third study was conducted in which $0.4 \mathrm{mg} / \mathrm{kg}$ of marijuana containing 3.12 percent and 6.24 percent THC was combusted per toke. Originally, as in the previous studies, we planned to teat six volunteers. However, the smoking of the high-potency marijuana induced postural hypotension and bradycardia (vasovagal syndrome) in the third and fourth subjects tested. Because of this undesirable side effect, the study was terminated after testing only three subjects. We are perplexed by the occurrence of this syndrome because we have never observed it in response to marijuana cigarette smoking. We have, however, observed the occurrence this syndrome in some subjects after the oral administration of high doses of THC (35 mg) or after the intravenous infusion of THC.

\section{Results}

THC Plasma Concentrations. As illustrated in figure 8, the THC plasma concentrations increased progressively for as long as tokes were taken. As a result, peak THC concentrations occurred in close proximity to the end of the smoking period (table 2). This finding suggests that the inhalation of a large volume of smoke (approximately $200 \mathrm{ml}$ ) every 2.5 minutes delivers enough THC to the blood stream to balance the drug's rate of disappearance into the extravascular compartment. In this respect, the results of marijuana water-pipe smoking are comparable to the results of accelerated marijuana cigarette smoking.

Contrary to our expectations, peak THC plasma concentrations varied widely among the subjects who participated in the studies (table 2). This result is disappointing because it demonstrates our failure to reduce the variability in peak THC plasma concentrations, despite controlling the amount of marijuana combusted per toke, the number of tokes taken, and the interval 

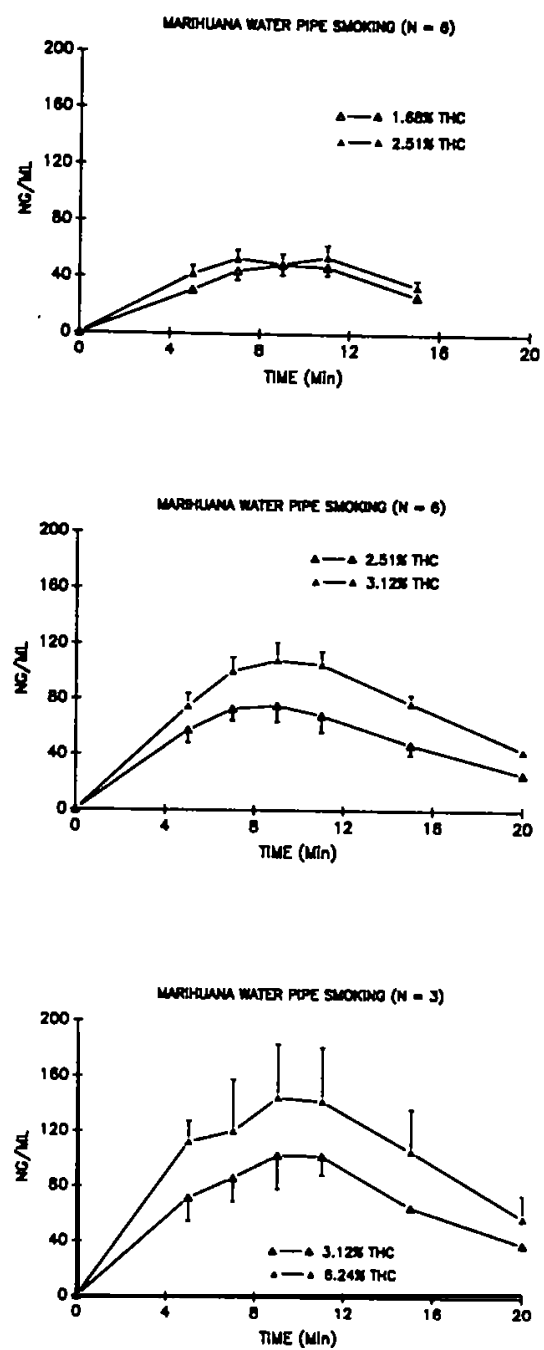

FIGURE 8. Comparison of the magnitude of THC plasma concentrations produced by marijuana water-pipe smoking over time

between tokes. It should be noted, however, that smoking factors other than those controlled in this study may have influenced the magnitude of the THC plasma concentrations observed. For example, although the subjects were instructed to hold the smoke inhaled for a period of 10 seconds, this requirement was not enforced. Therefore, according to their custom, 
many subjects held the smoke for longer intervals of time. Likewise, it was not possible to maintain a constant puff volume because uncontrolled amounts of atmospheric air were drawn to facilitate inhalation of the smoke produced by the combustion of each toke.

TABLE 2. Comparison of the THC plasma concentrations produced by marijuana water-pipe smoking

\begin{tabular}{|c|c|c|c|}
\hline Potency & $\begin{array}{c}\text { Time to Peak } \\
(\mathrm{min})\end{array}$ & $\begin{array}{c}\text { Peak Value } \\
(\mathrm{ng} / \mathrm{ml})\end{array}$ & $\begin{array}{l}\text { Range } \\
(\mathrm{ng} / \mathrm{ml})\end{array}$ \\
\hline \multicolumn{4}{|c|}{ First Study $(n=6)$} \\
\hline $\begin{array}{ll}1.68 \% & \mathrm{THC} \\
2.51 \% & \mathrm{THC}\end{array}$ & $\begin{array}{l}9.7 \pm 0.8 \\
8.3 \pm 1.0\end{array}$ & $\begin{array}{l}53.7 \pm 6.0 \\
58.8 \pm 7.6\end{array}$ & $\begin{array}{l}40.9-72.7 \\
34.9-81.8\end{array}$ \\
\hline \multicolumn{4}{|c|}{$\underline{\text { Second Study }(n=6)}$} \\
\hline $\begin{array}{ll}2.51 \% & \mathrm{THC} \\
3.12 \% & \mathrm{THC}\end{array}$ & $\begin{array}{l}7.7 \pm 0.7 \\
9.0 \pm 0.7\end{array}$ & $\begin{array}{c}79.7 \pm 10.8 \\
114.5 \pm 10.4\end{array}$ & $\begin{array}{l}39.0-116.0 \\
80.8-150.0\end{array}$ \\
\hline \multicolumn{4}{|c|}{ Third Study $(\mathrm{n}=3)$} \\
\hline $\begin{array}{ll}3.12 \% & \mathrm{THC} \\
6.24 \% & \mathrm{THC}\end{array}$ & $\begin{array}{l}10.3 \pm 0.7 \\
8.3 \pm 1.8\end{array}$ & $\begin{array}{l}109.6 \pm 20.8 \\
151.7 \pm 37.0\end{array}$ & $\begin{array}{l}81.0-150.0 \\
90.2-218.0\end{array}$ \\
\hline
\end{tabular}

NOTE: Despite controlled conditions, THC plasma concentrations varied widely among the subjects tested.

Subjective Effects. The mean subjective rating of high over the time of observation is illustrated in figure 9. It can be seen that the magnitude of subjective high increased progressively during smoking and for several minutes after its termination. Peak values occurred approximately 20 minutes after the beginning of smoking, i.e., approximately 10 minutes after the occurrence of peak THC plasma concentrations (table 3). Although peak subjective effects and AUC (0-35') values increased proportionally to the magnitude of the THC plasma concentrations obtained, statistical analysis of this limited amount of data indicates that no significant correlation is present between peak THC plasma concentrations and peak subjective effects $(\mathrm{r}=.153, \mathrm{t}=0.82, \mathrm{p}$ NS). This lack of correlation is probably due to the large intersubject variations in both plasma THC concentrations and subjective effects.

Heart Rate Effects. The mean heart rate acceleration over the time of observation is illustrated in figure 10. The changes in heart rate produced by marijuana pipe smoking mimic in all respects the subjective rating of high. Thus, the heart rate accelerated progressively during smoking and for 

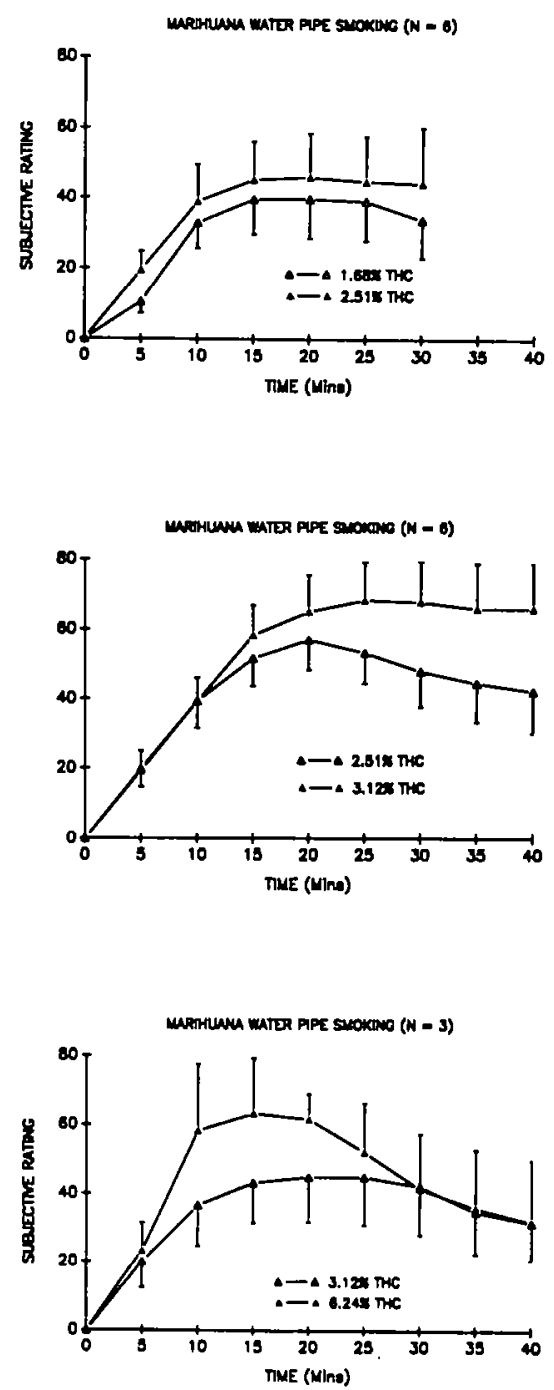

FIGURE 9. Comparison of the magnitude of the subjective rating of high produced by marijuana water-pipe smoking over time

several minutes after its termination. Peak values occurred approximately 20 minutes after the beginning of smoking i.e., approximately 10 minutes after the occurrence of peak THC plasma concentrations (table 3).

Likewise, mean peak heart rates and AUC (0-35') values increased proportionally to the magnitude of the THC plasma concentrations obtained. 
TABLE 3. Comparison of the pharmacologic effects produced by marijuana after pipe smoking

\begin{tabular}{|c|c|c|}
\hline Time to Peak & Peak Value & AUC (0-35') \\
\hline \multicolumn{3}{|c|}{ Subjective Rating of High } \\
\hline \multicolumn{3}{|c|}{ First Study $(\mathrm{n}=6)$} \\
\hline $18.3 \pm 2.5$ & $41.7 \pm 10.5$ & $980 \pm 221$ \\
\hline $18.3 \pm 1.7$ & $48.3 \pm 11.9$ & $1,071 \pm 265$ \\
\hline \multicolumn{3}{|c|}{ Second Study $(n=6)$} \\
\hline $20.0 \pm 2.2$ & $57.5 \pm 8.9$ & $1,457 \pm 249$ \\
\hline $28.3 \pm 4.0$ & $73.0 \pm 10.4$ & $1,754 \pm 282$ \\
\hline \multicolumn{3}{|c|}{ Third Study $(n=3)$} \\
\hline $2.0 \pm 5.0$ & $50.7 \pm 12.9$ & $1,270 \pm 368$ \\
\hline $13.3 \pm 3.3$ & $68.3 \pm 13.6$ & $1,595 \pm 409$ \\
\hline \multicolumn{3}{|c|}{ Percent Heart Rate Acceleration } \\
\hline \multicolumn{3}{|c|}{$\underline{\text { Second Study }(\mathrm{n}=6)}$} \\
\hline $20.8 \pm 2.7$ & $34.4 \pm 6.2$ & $492 \pm 151$ \\
\hline $21.7 \pm 2.1$ & $53.6 \pm 5.5$ & $862 \pm 96$ \\
\hline \multicolumn{3}{|c|}{ Third Study $(n=3)$} \\
\hline $14.0 \pm 0.0$ & $70.4 \pm 3.0$ & $1,377 \pm 293$ \\
\hline $18.0 \pm 2.0$ & $74.9 \pm 18.0$ & 1,589322 \\
\hline
\end{tabular}

NOTE: The heart rate was not measured in the first study.

Nonetheless, statistical analysis indicates that no significant correlation is present between peak THC plasma concentrations and peak heart rate acceleration $(\mathrm{r}=.385, \mathrm{t}=1.67$, $\mathrm{p}$ NS). This is probably due to the large intersubject variations in plasma THC concentrations and heart rate accelerations.

\section{AMOUNT OF THC TRAPPED IN TEE UPPER RESPIRATORY TRACT MUCOSA}

The results of several independent studies indicate that THC is present in saliva and that its concentration declines with time after marijuana smoking (Hawks 1984; Cross et al. 1987; Maseda et al. 1986; Thompson and Cone 1987). The presence of THC in saliva after marijuana smoking is not due to its secretion by the salivary glands. This is demonstrated by the results of experiments in which we administered radioactively labeled THC orally 

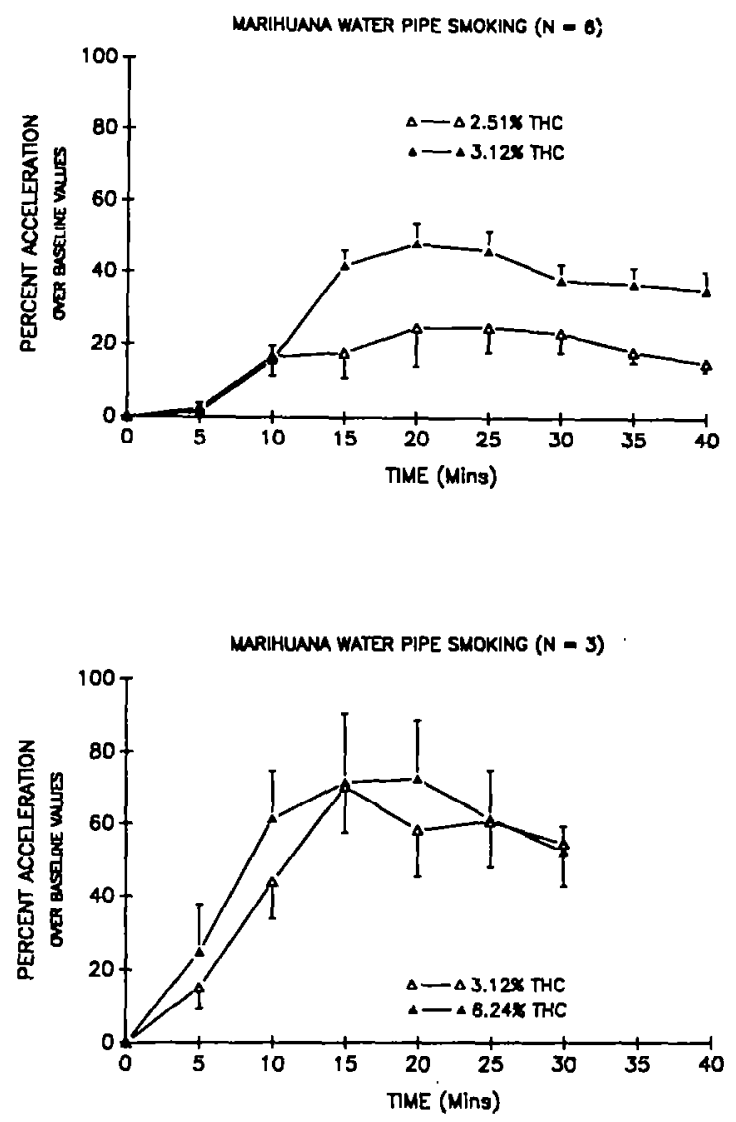

FIGURE 10. Comparison of magnitude of mean hem rate acceleration produced by marijuana water-pipe smoking over time

and intravenously to normal volunteers (Perez-Reyes et al. 1972; PerezReyes et al. 1973). In these experiments we collected timed saliva samples after drug administration. No radioactivity was detected in any of the saliva samples assayed. This observation indicates that neither THC nor its me tabolities are excreted by the salivary glands. Therefore, the THC present in saliva derives from that sequestered in the buccal mucosa during smoking.

The amount of THC trapped in the buccal mucosa or present in mixed saliva samples is time and dose dependent. This is demonstrated by a study in which 30 volunteers smoked NIDA marijuana cigarettes containing either 
2.49 percent (18 subjects) or 4.84 percent (12 subjects) THC blindly. The mean amount of THC present in swabs of the buccal mucosa and the mean amount of THC present in 25 microliters of mixed saliva samples are shown in table 4 . Because the THC present in the swabs cannot be accurately related to a volume of saliva, we have reported them as amounts instead of concentrations. The largest amounts of THC in swab and saliva, irrespective of the marijuana potency smoked, were observed at the first time of measurement (i.e., 1 hour after the initiation of smoking). After this time, mean THC amounts declined progressively to minimal but still detectable values at the 4-hour end of the study.

TABLE 4. Comparison of the mean amounts of THC (ng) measured in 25 microliters of saliva and swabs of the roof of the mouth and tongue

\begin{tabular}{lrrrrr}
\hline & \multicolumn{2}{c}{$2.40 \% \mathrm{THC}$} & & \multicolumn{2}{c}{$4.84 \% \mathrm{THC}$} \\
\cline { 2 - 3 } \cline { 6 - 6 } & Swab & Saliva & & Swab & Saliva \\
\hline 1 Hour & $16.9 \pm 7.2$ & $20.9 \pm 8.2$ & & $59.8 \pm 27.5$ & $60.5 \pm 24.9$ \\
2 Hours & $7.8 \pm 3.7$ & $5.8 \pm 1.8$ & & $26.5 \pm 12.3$ & $26.7 \pm 14.8$ \\
3 Hours & $7.1 \pm 3.8$ & $4.1 \pm 1.3$ & & $16.6 \pm 8.9$ & $6.9 \pm 2.7$ \\
4 Hours & $3.8 \pm 1.7$ & $1.9 \pm 0.8$ & & $13.5 \pm 7.4$ & $4.2 \pm 1.7$ \\
\hline
\end{tabular}

Since THC is trapped in the buccal mucosa, it is reasonable to assume that THC is also trapped in the mucosa of the other parts of the upper respiratory tract, i.e., pharynx, larynx, trachea, and bronchi. Obviously, it is not possible to know the amount of THC that is trapped in the combined surface. area of these anatomical structures during marijuana smoking. However, judging by the relatively small amounts of THC trapped in the buccal mucosa (i.e., less than $100 \mathrm{ng}$ in either swabs or 25 microliters of saliva 1 hour after smoking) the total amount of THC trapped in the mucosa of the upper respiratory tract can be considered to be a factor of minor importance with regard to the bioavailability of $\mathrm{THC}$

\section{CONCLUSION}

Although smoking is a practical method for the delivery of marijuana's active principle (THC), many factors inherent in the smoking process decrease the drug's bioavailability. For example, whether marijuana is smoked in pipe or cigarette form, 23 to 30 percent of its THC content is destroyed by pyrolysis; if marijuana is smoked in cigarette form, as much as 40 to 50 percent of $\mathrm{THC}$ can be lost in sidestream smoke. 
There is a significant correlation between the potency of the marijuana smoked and the magnitude of the THC plasma concentrations obtained. However, large interindividual variations in peak THC plasma concentrations occurred across all of the marijuana potencies investigated. These results were obtained in experiments in which the volunteers smoked marijuana cigarettes in their customary fashion (uncontrolled smoking). To reduce this variability, experiments were conducted in which marijuana was smoked in a water pipe. This method of smoking permits control of the amount of marijuana combusted per toke, the number of tokes taken, and the interval between tokes. Despite controlling these important smoking factors, large interindividual variations in the magnitude of the THC plasma concentrations obtained continued to be observed.

During marijuana smoke inhalation, THC is trapped in the mucosa of the upper respiratory tract, thereby reducing the drug's bioavailability. Judging by the amounts of THC measured in saliva or swabbings of the buccal mucosa, however, the total loss of THC by this factor can be considered of minor importance.

In summary, marijuana smoking is a complex process that does not permit controlled dosing. Therefore, for research or therapeutic purposes, it is indispensable to measure the THC plasma concentrations to know how efficiently a given individual smoked.

\section{REFERENCES}

Cook, C.E.; Seltzman, H.H.; Schindler, V.H.; Tallent, C.R.; Chin, KM.; and Pitt, C.G. Radioimmunoassays for cannabinoids. In: Hawks, R.L., and Willette, R.E., eds. The Analysis of Cannabinoids in Biological Fluids. National Institute on Drug Abuse Research Monograph 42. NTIS Pub. No. 83-136044. Springfield, VA: U.S. Dept. of Commerce, 1982. pp. 19-32.

Davis, K.H.; McDaniel, I.A.; Caddell, L.W.; and Moody, P.L. Some smoking characteristics of marijuana cigarettes. In: Agurell, S.; Dewey, W.L.; and Willette, R.E., eds. The Cannabinoids: Chemical, Pharmacologic, and Therapeutic Aspects. New York: Academic Press, 1984. pp. 97-109. Gross, S.J.; Worthy, T.E.; Nerder, L.; Zimmerman, E.G.; Soares, J.R.; and Lomax, P. Detection of recent cannabis use by saliva ${ }^{9}$-THC radio immunoassay. J Anal Toxicol 9:91-97, 1987.

Hawks, R.L. Developments in cannabinoid analyses of body fluids: Implications for forensic applications. In: Agurell, S.; Dewey, W.L.; and Willette, R.E., eds. The Cannabinoids: Chemical, Pharmacologic, and Therapeutic Aspects. New York: Academic Press, 1984. pp. 123-134. 
Hutcheson, J.S.; Perez-Reyes, M.; and Di Guiseppi, S. An automated computer-based system for the study of marijuana smoking dynamics. In: Agurell, S.; Dewey, W.L.; and Willette, R.E., eds. The Cannabinoids: Chemical, Pharmacologic, and Therapeutic Aspects. New York: Academic Press, 1984. pp. 111-121.

Maseda, C.; Hama, K.; Fukui, Y.; Matsubara, K.; Takahashi, S.; and Akane, A. Detection of ${ }^{9}$-THC in saliva by capillary GC/ECD after marihuana smoking. Forensic Sci Int 32:259-266, 1986.

Owens, S.M.; McBay, A.J.; Reisner, H.M.; and Perez-Reyes, M. ${ }^{125}$ I Radioimmunoassay of ${ }^{9}$-tetrahydrocannabinol in blood and plasma with a solidphase second-antibody separation method. Clin Chem 27:619-624, 1981.

Perez-Reyes, M.; Di Guiseppi, S.; Davis, H.H.; Schindler, V.H.; and Cook, C.E. Comparison of effects of marihuana cigarettes of three different potencies. Clin Pharmacol Ther 31:617-624, 1982.

Perez-Reyes, M.; Lipton, M.A.; Timmons, M.C.; Wall, M.E.; Brine, D.R.; and Davis, K.H. Pharmacology of orally administered ${ }^{9}$-tetrahydrocannabinol. Clin Pharmacol Ther 14:48-55, 1973.

Perez-Reyes, M.; Owens, S.M.; and Di Guiseppi, S. The clinical pharmacology and dynamics of marihuana cigarette smoking. J Clin Pharmacol 21:201S-207S, 1981.

Perez-Reyes, M.; Timmons, M.C.; Lipton, M.A.; Davis, K.H.; and Wall, M.E. Intravenous injection in man of ${ }^{9}$-tetrahydrocannabinol and $11-\mathrm{OH}-$ 9-tetrahydrocannabinol. Science 177:633-635, 1972.

Thompson, L.K., and Cone, E.J. Determination of ${ }^{9}$-tetrahydrocannabinol in human blood and saliva by high-performance liquid chromatography with amperometric detection. J Chromatogr 421:91-97, 1987.

\section{ACKNOWLEDGMENTS}

Supported by National Institute on Drug Abuse contracts 271-80-3705 and 271-87-8126 and grant DA 04484.

\section{AUTHOR}

Mario Perez-Reyes, M.D.

Professor

Department of Psychiatry

The University of North Carolina at Chapel Hill

CB \#7175, Medical Research Building A

Chapel Hill, NC 27599-7175 